\title{
CHALLENGES OF ALCOHOL TAXATION POLICIES AND ALCOHOL CONSUMPTION MEASUREMENT
}

\author{
Marko Šantek ${ }^{1}$ \\ Sonja Cindori ${ }^{2}$
}

DOI: https://doi.org/10.31410/ERAZ.2019.1

\begin{abstract}
Excessive alcohol consumption is a major health and social hazard of a modern society. Alcohol excise duties are important tool in hands of policymakers regarding possibilities to restrain and to control alcohol consumption. However, European Union directive 92/84/EEC undermines this potential with prescription of zero tax rates for wine which opens many doors of tax avoidance, substitution and smuggling opportunities. Regarding possible solutions, it is necessary to abolish zero tax rates for wine in European Union and to treat all alcoholic beverages equally in terms of taxation.
\end{abstract}

Keywords: alcohol, tax, excise, smuggling, health, wine, consumption.

\section{FOREWORD}

$\mathrm{T}$ his article will give a review of major challenges in the field of alcohol taxation policies and alcohol consumption measurement in order to give a clear picture to all parties interested in these fields, such as fiscal, health and social policy makers. Taxation of alcohol in European Union is regulated by Council Directive 92/93/EEC which prescribes various categories of alcoholic beverages which are subject of this policy, basis on which tax rate is calculated and various exemptions for industrial alcohol and possibilities for reduced rates for independent breweries [1], and Council Directive 92/84/EEC which sets the minimum rates of excise duties for alcohol and alcoholic beverages. Directive 92/84/EEC prescribes zero rates for wine and sparkling wine, which seriously undermines the potential of any alcohol related fiscal and social policy, giving consumers a lot of opportunities to avoid heavy taxed spirits or beer and to replace them with wine [2].

After foreword, first chapter will tackle more deeply into main reasons for imposing excise duties on alcohol, and second chapter will discuss consequences of alcohol excise duties increase. Third chapter will analyse methods of alcohol consumption measurement, and in conclusion main problems of current alcohol excise duties system in European Union will be pointed out.

\section{MAIN REASONS FOR IMPOSING ALCOHOL EXCISE DUTIES}

Excessive consumption of alcohol creates many problems for individuals, their families and society as a whole. There are many reasons for imposing alcohol excise duties, but most significant could be divided in three major categories - health, social and economic.

Alcohol is recognized as one of the leading causes of cancer and ill health, which contributes significantly to the increase of overall mortality rates within population. High levels of alcohol consumption in the long run increase the risk of liver cirrhosis and chronic pancreatitis [3].

\footnotetext{
1 Zagrebačka Banka, Unicredit Group, Samoborska cesta 145, Zagreb, Croatia

2 Faculty of law, University of Zagreb, Trg Republike Hrvatske 14, Zagreb, Croatia
} 
Alcohol is a substance which is an important risk factor for many types of cancer, such as liver, throat, esophagus, mouth and breast cancers, and to certain extent increases the risk of stomach and colon cancers [4].

Alcohol consumption can have many social consequences and negative external effects. Long term alcohol abuse can lead to alcohol dependence, which is a huge problem for the family of the addict and society as a whole. Linear relationship between alcohol and depression is proven [5]. Moreover, many traffic accidents are caused because of the drunk driving; compelling evidence exists about driver impairment when blood level of alcohol is above zero [6]. Furthermore, with higher levels of alcohol intoxication there is a greater probability for usage of emergency rooms or some extended medical treatment [7] and in such a way alcohol consumption increases costs of a public health system.

Main economic reason behind imposing of alcohol excise duties is mitigation of negative external effects which are caused by alcohol consumption, with the aim of reducing levels of alcohol consumption to the acceptable and sustainable levels, having in mind negative external effects [8]. On the other hand, excise duties are quite handy tool when government needs quickly to raise some funds, due to several key features of excise duties taxes. Firstly, they are very easy and cheap to collect in terms of government administrative effort since there is relatively small number of obligors. Furthermore, it will be hard for consumers to adjust levels of consumption accordingly to excise duties and prices of the products increase in the short run, thus giving government good possibility to collect significant funds if needed. Considering the above, excise duties remain very important instrument of fiscal and social policies in many countries.

\section{CONSEQUENCES OF ALCOHOL EXCISE DUTIES INCREASE}

In cases of strong increase of alcoholic beverages prices on a country level, there are negative effects which have to be pointed out. Main consequences are seen in the form of increased cross border trade, domestic alcohol production and consumption of alcohol which is determined for medical or industrial usage, or in the form of completely illegal activities such as smuggling [9]. As an example, budget losses which occurred on EU-15 level in 1996 due to illegal activities are estimated to the amount of 1,5 B EUR [10]. Bearing all this in mind, it is a strong necessity to envisage an effective system of control over the cross-border trade in order to decrease effects of smuggling of alcohol between countries. This can be a particularly tricky issue for countries with long borders with neighbouring countries, especially if these borders are also boundaries of supra national bodies or organisations such as European Union borders with third countries. Furthermore, country borders which are difficult to access and control due to their geological properties and remoteness present additional problems in effective control of cross border trade or smuggling activities. This is very prominent in mountain regions, which are quite often remote and not easily accessible by car or some other type of transport due to lack of infrastructure.

Another key thing to point out is the fact that generally, countries have different tax policies toward different types of alcoholic beverages. This is prominent in European Union, where many Mediterranean countries have very low or even zero tax rates on wine, because they are protecting domestic wine industry, and in the same time quite high tax rates on spirits [11]. Moreover, all these discrepancies are aligned with European Union directives and guidelines regarding alcohol taxation. With such alignment, it is difficult to perform any systematic tax policy related to control of alcohol consumption within population, because consumers can easily 
avoid higher taxes on spirits or beer and replace them with more quantity of wine, either in their home country or neighbouring country. Directive 92/84/EEC prescribes minimum excise duty rate for spirits at 550 EUR per hectoliter of pure alcohol, for beer at 1.87 EUR per hectoliter of finished product, but wine and sparkling wine have a minimum rate of zero EUR per hectoliter of finished product [11].

Bearing this in mind, it is impossible to envisage successful tax policy which aims to reduce or restrain consumption of alcohol due to complete ignorance of substitution effect. If there is a huge price increase of certain good or service, it should be expected that consumers will try to purchase other goods or services of similar qualities, but with lower price. If policymakers have a goal to reduce consumption of certain goods or services, then it is reasonable to make sure that all goods or services of the same qualities or type are treated the same, without giving preferential status to some particular subtypes of goods or services. In this particular case, if there is an intention to reduce consumption of alcoholic beverages, then it is necessary to treat equally or very similarly all beverages that are encompassed under definition of alcoholic drinks.

To sum it up, all drinks that contain the substance of alcohol should be treated equally regarding taxation policy. Current situation regarding excise duties on alcoholic beverages in European Union is not balanced because wine is treated preferentially with respect to other types of alcoholic beverages. Possible reasons of preferential wine status could be found in the support of domestic wine industry, but that is completely in collision with the goals of reducing alcohol consumption and already mentioned health and social policies.

\section{PROBLEMS WITH ALCOHOL CONSUMPTION MEASUREMENT}

When evaluation efficiency of alcohol related policies, it is very important to be able to correctly measure amounts of alcoholic drinks which are consumed in a given period of time in a given country. Thus, two main approaches were developed - measuring alcohol consumption through retail sales data or through surveys.

Retail sales data are considered more accurate in terms of estimating how much alcohol was consumed by the population in a given year, because governments monitor sales data for tax collection purposes, and these can be obtained from government publications or agencies. However, these data are still limited because they cannot show how much alcohol was home-brewed or the magnitude of alcohol smuggling activities, since these cannot be visible from retail sales data. Moreover, retail sales measures are usually focused on measuring how much alcohol was consumed in a country during a year, thus it is impossible to determine how much alcohol consumed natives or tourists in a given year.

On the other hand, measurement through surveys offers few unique benefits. First, they can distinguish between abstainers and the people that are actually doing all the drinking. Moreover, survey data have the ability to compare various sub-populations of interest defined by socio-demographic and other individual level characteristics and potential to assess drinking patterns which cannot be done through a measurement using retail sales data, however, in surveys people tend to underestimate their level of alcohol consumption, and are generally unwilling to admit their real level of alcohol intake, since that is a rather sensitive, delicate and private matter [12]. 


\section{CONCLUSION*}

Consumption of alcohol remains huge health and social issue in many countries, especially in the European Union and in countries which emerged after Soviet Union collapse. However, there are no easy solutions available in order to effectively reduce alcohol consumption and alcohol related harm. This is mainly due to inability of efficient monitoring of alcohol production, effective monitoring of cross border trade and prevention of smuggling on an international scale. Even in European Union, countries have different laws regarding taxation of alcoholic beverages, and that also somewhat hinders the ability of alcohol taxation policies in certain countries due to many alternatives that are available to consumers of alcoholic beverages.

Furthermore, additional problems are present with measurement of alcohol consumption, since retail sales data cannot give precise information regarding drinking patterns within population or magnitude of smuggling activities, and surveys are vulnerable to underestimation of alcohol consumption by respondents due to sensitivity of questions related to alcohol consumption. To sum it up, more synergy and cooperation between counties should be envisaged in order to achieve higher levels of efficiency in monitoring of alcohol cross border trade and prevention of smuggling activities.

Another key thing to point out is that countries of European Union need to achieve some general consensus regarding the tax status of wine. If policymakers of European Union countries are fully aware of alcohol related harm, and if they reach a conclusion that prevention of these negative health and social effects is far more important than stimulation of wine industry, than it will be necessary to abolish zero tax rates on wine within European Union, and to set tax rates on wine comparable to those on spirits or beer.

\section{REFERENCES}

[1] Council Directive 92/83/EEC on the harmonisation of the structure of excise duties on alcoholic beverages and alcohol contained in other products, from 19 ${ }^{\text {th }}$ of October 1992 (OJ L 316, 31.10.1992, p. 21-27)

[2] Council Directive 92/84/EEC on approximation of the rates of excise duties on alcohol and alcoholic beverages from $19^{\text {th }}$ of October 1992 (OJ L 316, 31.10.1992, p. 29-31)

[3] Corrao, G., Bagnardi, V., Zambon, A., Arico, S. (1999), Exploring the dose-response relationship between alcohol consumption and the risk of several alcohol-related conditions: a meta-analysis, Addiction, London, United Kingdom, Oct;94(10), p. 1551-1573

[4] Bagnardi V, Blangiardo M, La Vecchia C, Corrao G., 2001, A meta-analysis of alcohol drinking and cancer risk, Br J Cancer, London, United Kingdom, Nov 30;85(11), p. 17001705

[5] Alati, R., Lawlor, D. A., Najman, J. M., Williams, G.M., Bor, W., O’Callaghan, M. (2005), Is there really $a, J$-shaped' curve in the association between alcohol consumption and symptoms of depression and anxiety? Findings from the Mater-University Study of Pregnancy and its outcomes, Addiction, London, United Kingdom, May;100(5), p. 643-651

[6] Moskowitz, H., Fiorentino, D. (2000), A review of the literature on the effects of low doses of alcohol on driving-related skills, US Department of transportation, Springfield, Virginia, USA, p. 4-16. Retrieved at: https://doi.org/10.1080/15389580490465201, (30/01/2019)

* Opinions or statements of the authors don’t represent opinions or statements of Unicredit Group or Zagrebačka Banka. 
[7] Cherpitel, C. (2014), Focus on: The Burden of Alcohol Use - Trauma and Emergency Outcomes, Alcohol Res, USA, 35(2), p. 150-154

[8] Cnossen, S. (2006), Alcohol Taxation and Regulation in the European Union, CESifo Working Paper No. 1821, Cesifo, Munich, Germany, p. 10-22

[9] Anderson, P., Baumberg, B. (2006), Alcohol in Europe - A public health perspective, Institute of Alcohol Studies, London, United Kingdom, p. 47-70

[10] High Level Group on Fraud in the Tobacco and Alcohol Sectors (1998), Report to Directors General for Customs and Indirect Taxation, European Commission, Bruxelles, Belgium, p. 10

[11] European Commission, (2013), Excise duty tables - Part I Alcoholic Beverages - Situation at 1st January 2013, European Commission, Bruxelles, Belgium, p. 6-38

[12] World Health Organization (2000), International guide for monitoring alcohol consumption and related harm, World health organization, Geneva, Switzerland, p. 21-59 